\title{
Polymorphic variants in the dopamine receptor D2 in women with endometriosis-related infertility
}

\author{
MALGORZATA SZCZEPAŃSKA ${ }^{1}$, ADRIANNA MOSTOWSKA ${ }^{2}$, PRZEMYSLAW WIRSTLEIN ${ }^{1}$, \\ JANA SKRZYPCZAK ${ }^{1}$, MATTHEW MISZTAL ${ }^{2}$ and PAWEŁ P. JAGODZIŃSKI ${ }^{2}$ \\ ${ }^{1}$ Department of Obstetrics, Gynecology and Gynecological Oncology, Division of Reproduction; \\ ${ }^{2}$ Department of Biochemistry and Molecular Biology, Poznan University of Medical Sciences, Poznań 60-781, Poland
}

Received June 23, 2014; Accepted March 16, 2015

DOI: $10.3892 / \mathrm{mmr} .2015 .3733$

\begin{abstract}
Data suggests that dopamine receptor DRD2 gene variants may contribute to hyperprolactinemia and that they may be risk factors for endometriosis-related infertility. The purpose of the present study was to determine whether nucleotide variants of the DRD2 gene may be associated with infertility related to endometriosis. Five DRD2 SNPs, rs1800497, rs6277, rs2283265, rs4245146 and rs4648317, which are located in different blocks of linkage disequilibrium, were studied in 151 cases and 381 controls. No significant differences between DRD2 rs1800497, rs6277, rs2283265, rs4245146 and rs4648317 genotype, allele nor haplotype frequencies were observed in women with endometriosis-related infertility compared with the control group. The present results did not confirm DRD2 gene variants to be genetic risk factors for endometriosis-related infertility.
\end{abstract}

\section{Introduction}

The frequency of endometriosis among infertile women diagnosed by laparoscopic examination ranges from 20 to $50 \%$ (1). Patients with endometriosis-related infertility frequently display increased blood plasma levels of prolactin (1). It has been hypothesized that hyperprolactinemia may result in endometriosis-related infertility and that fertility may be restored by prolactin suppression $(1,2)$. Increased levels of prolactin result in anovulation, by blocking estrogen receptor function in the hypothalamus (3). The effect of raised levels of prolactin on the ovary may also reduce affinity of LH receptors in the corpus luteum and decrease the biosynthesis of progesterone, leading to anovulation and suppression of follicular maturation (3). Furthermore, prolactin may contribute to the

Correspondence to: Professor Paweł P. Jagodziński, Department of Biochemistry and Molecular Biology, Poznan University of Medical Sciences, 6 Święcickiego, Poznań 60-781, Poland E-mail: pjagodzi@am.poznan.pl

Key words: dopamine receptor D2 gene variants, endometriosis, infertility pathogenesis of endometriosis by supporting angiogenesis (4), which initiates and enhances endometrial lesions (5).

Estrogen supports the proliferation of anterior pituitary lactotroph cells, and induces prolactin gene transcription and protein release from the anterior pituitary gland (6). By contrast, the hypothalamus exerts a tonic inhibitory action against prolactin via the excretion of dopamine from the portal vessels of the pituitary (6). There are two subfamilies of dopamine receptors: DRD1, which stimulates adenylyl cyclase activity; and DRD2, which inhibits the activity of this enzyme (7). The adenohypophysis primarily expresses the DRD2 dopamine receptor (7). Dopamine binds to DRD2 in the pituitary lactotrophs and decreases the level of intracellular cyclic adenosine monophosphate, which in turn inhibits prolactin secretion (8).

Data suggests that $D R D 2$ gene variants may contribute to hyperprolactinemia $(9,10)$. Furthermore, it has been demonstrated that the DRD2 single nucleotide polymorphism (SNP), $3438 \mathrm{C}>\mathrm{T}$ (rs6277), at proline codon in exon 7, is associated with an increased risk of moderate/severe peritoneal endometriosis in women with infertility (11). In order to evaluate whether $D R D 2$ gene variants are genetic risk factors for endometriosis-related infertility in women from a Polish population, the rs1800497, rs6277, rs2283265, rs4245146 and rs4648317 SNPs, which are located in different blocks of linkage disequilibrium (LD), were selected for further investigation.

\section{Materials and methods}

Patients and controls. Peripheral blood samples from females with endometriosis-related infertility and fertile controls, were obtained from the Gynecologic and Obstetrical University Hospital, Division of Reproduction at Poznań University of Medical Sciences (Poznań, Poland). The studied population was divided into two groups: Those with endometriosis and infertility (151), and a fertile control group (381) (Table I). The following inclusion criteria for infertile women with endometriosis were used: No anatomical changes in the reproductive tract, no hormonal treatment, a minimum 1 year of infertility and a current desire to achieve conception. The exclusion criteria were as follows: Male factor infertility, polycystic ovary syndrome (PCOS), mechanical distortion of the endometrial cavity by fibroids and bilateral tubal occlusion. All 


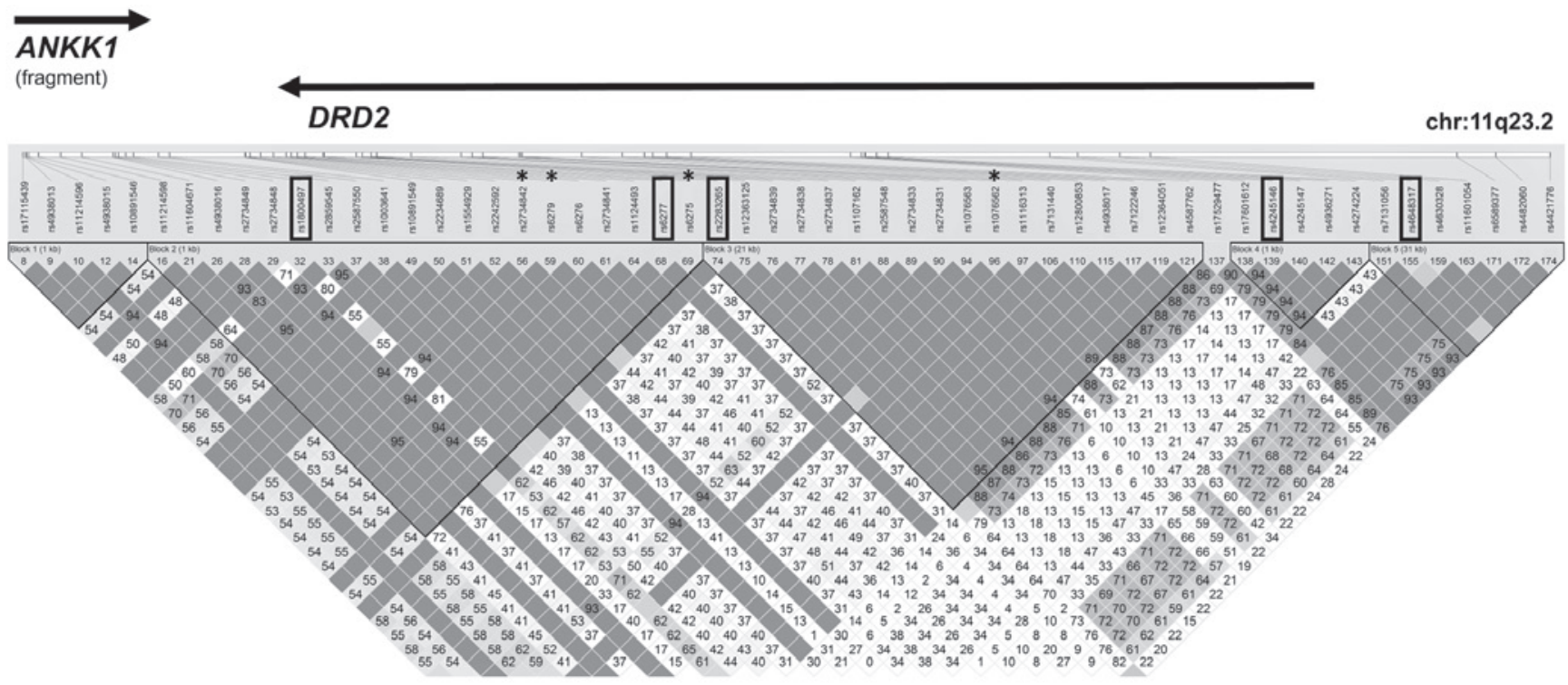

Figure 1. LD plot of HapMap SNPs within the DRD2 gene region. The plot was generated using genotype data from HapMap CEU samples and the Haploview 4.0 software. The names of the examined SNPs are enclosed in boxes and * corresponds to HapMap-available SNPs cited in the Discussion section. Numbers in the squares indicate the percentage of LD between a given pair of SNPs (D'-values). LD, Linkage Disequilibrium; DRD2, dopamine receptor D2.

patients with endometriosis received laparoscopic and histological diagnoses of endometriosis. The stage of endometriosis was evaluated according to the revised classification of the American Society for Reproductive Medicine (rASRM) (12).

All fertile women assigned to the control group were examined for the cause of pelvic pain. However, the laparoscopy evaluation did not demonstrate any pelvic abnormalities. The controls were diagnosed by laparoscopy with varicose veins in the pelvic floor, and exhibited no signs of past or present inflammation. The following inclusion criteria for the fertile controls were used: Regular menses, no anatomical changes in the reproductive tract, no hormonal treatments, and $\geq 1$ child born $\leq 1$ years prior to the laparoscopy (Table I). The exclusion criteria were as follows: Diagnosis of past or present inflammation, pelvic abnormalities, endometriotic lesions and PCOS. Patients and controls were matched by age, and were all Caucasians of Polish descent (Table I). Written and verbal consent was obtained from all participating individuals. The study procedures were approved by the Local Ethical Committee of Poznań University of Medical Sciences.

Genotyping. Genomic DNA was obtained from peripheral blood leukocytes using salt extraction. The DNA samples were subsequently genotyped for the 5 SNPs in DRD2 (Table II and Fig. 1). SNPs were selected using the genome browser of the International HapMap Consortium (http://www.hapmap. org/index.html.en), UCSC (http://genome.ucsc.edu) and dbSNP database (http://www.ncbi.nlm.nih.gov/projects/SNP/). SNPs were selected based on functional significance, location in the distinct LD blocks and minor allele frequency (MAF) of $>0.1$ in the Caucasian population.

Genotyping of DRD2 rs2283265, rs4245146 and rs4648317 was conducted by high-resolution melting (HRM) using the HOT FIREPol EvaGreen HRM mix (Solis BioDyne, Tartu, Estonia), on the LightCycler 480 system (Roche Diagnostics, Mannheim, Germany). Evaluation frequency of DRD2
Table I. Clinical characteristics of patients.

\begin{tabular}{lcc}
\hline Characteristic & Endometriosis & Controls \\
\hline Number of patients & 151 & 381 \\
Age in years (range) & $32(21-42)$ & $32(20-39)$ \\
Parity & NA & $1(1-4)$ \\
$\begin{array}{l}\text { Duration of infertility } \\
\text { in years (range) }\end{array}$ & $3(1-7)$ & NA \\
rASRM stage & & \\
Stage I & & \\
Stage II & $(\mathrm{n}=83)$ & NA \\
\hline
\end{tabular}

Data are presented as the median (range). rASRM, revised American society for reproductive medicine classification (12); NA, not applicable.

rs1800497 and rs6277 was performed using polymerase chain reaction (PCR), followed by digestion by the appropriate restriction enzyme (PCR-RFLP), according to the manufacturer's instructions (Fermentas, Vilnius, Lithuania), and $3 \%$ agarose separations (Serva, Heidelberg, Germany). The primary sequences and conditions for HRM and PCR-RFLP analyses are presented in Table II. Genotyping quality was evaluated by repeated genotyping of a random selection of $10 \%$ of the study population.

Statistical analysis. For each SNP, the Hardy-Weinberg equilibrium (HWE) was assessed using Pearson's goodness-of-fit $\chi^{2}$ statistic. The differences in the allele and genotype frequencies between cases and controls were determined using standard $\chi^{2}$ or Fisher tests. Odds ratios (OR) and the associated $95 \%$ confidence intervals ( $95 \% \mathrm{CI}$ ) were also calculated. The data was analyzed under recessive and dominant inheritance models. For the additive inheritance model, SNPs were tested 

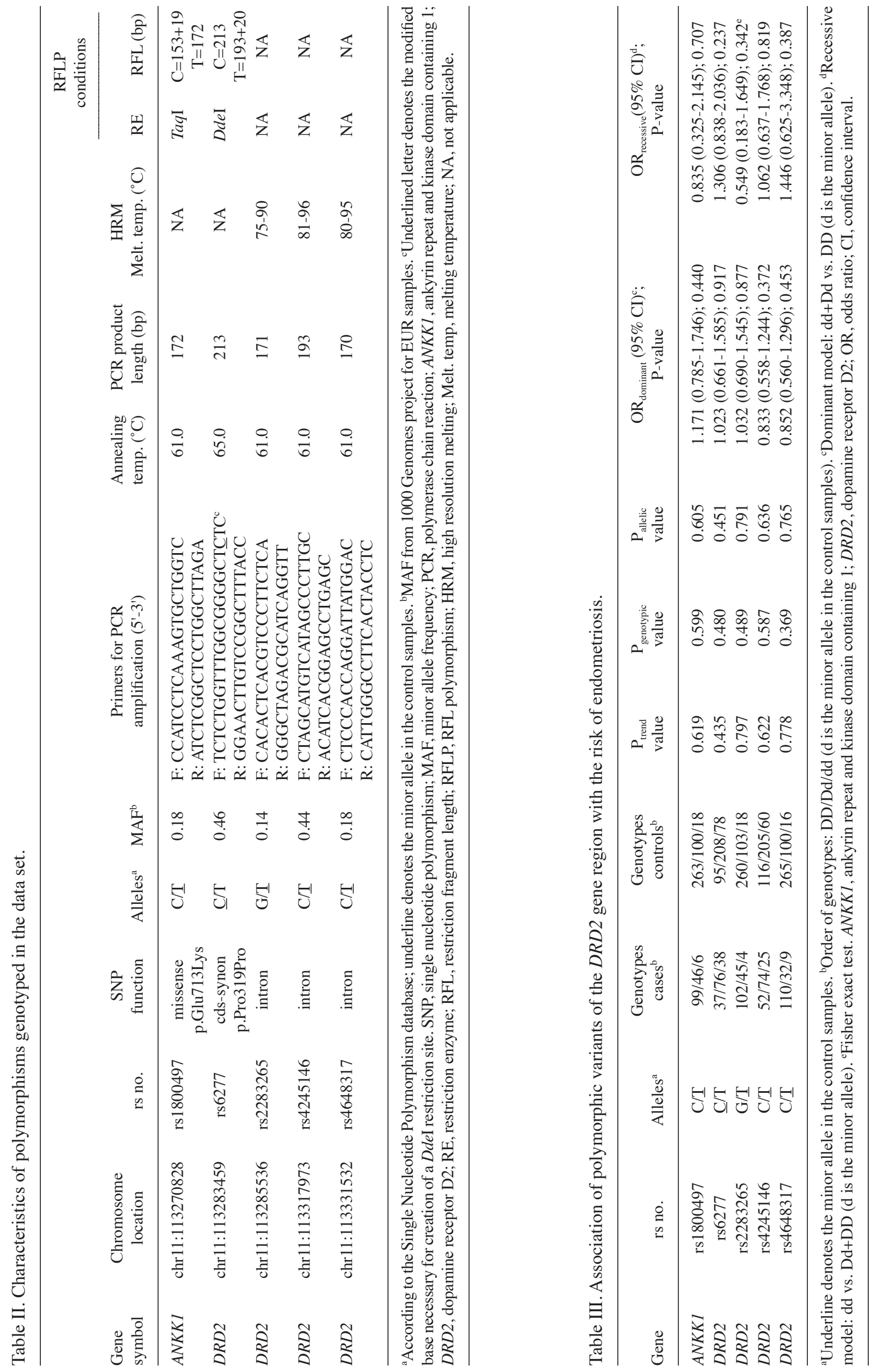
Table IV. Haplotype analysis of SNPs genotyped in the DRD2 gene region.

\begin{tabular}{|c|c|c|c|c|c|c|}
\hline \multirow[b]{2}{*}{ Polymorphism } & \multirow[b]{2}{*}{ Haplotype } & \multicolumn{2}{|c|}{ Frequency } & \multirow[b]{2}{*}{$\chi^{2}$} & \multirow[b]{2}{*}{$\mathrm{P}$-value } & \multirow[b]{2}{*}{$\mathrm{p}_{\text {corr }}$ value $^{\mathrm{a}}$} \\
\hline & & All individuals & Case, control & & & \\
\hline \multirow[t]{4}{*}{ rs1800497_rs6277 } & $\mathrm{CT}$ & 0.484 & $0.473,0.488$ & 0.199 & 0.656 & 0.949 \\
\hline & $\mathrm{CC}$ & 0.333 & $0.333,0.333$ & 0.000 & 0.993 & 1.000 \\
\hline & $\mathrm{TC}$ & 0.152 & $0.170,0.145$ & 1.032 & 0.310 & 0.635 \\
\hline & $\mathrm{TT}$ & 0.031 & $0.024,0.033$ & 0.638 & 0.425 & 0.791 \\
\hline \multirow[t]{4}{*}{ rs6277_rs2283265 } & TG & 0.492 & $0.487,0.495$ & 0.055 & 0.815 & 0.994 \\
\hline & CG & 0.327 & $0.336,0.324$ & 0.143 & 0.706 & 0.971 \\
\hline & $\mathrm{CT}$ & 0.158 & $0.167,0.155$ & 0.247 & 0.619 & 0.945 \\
\hline & $\mathrm{TT}$ & 0.023 & $0.011,0.027$ & 2.643 & 0.104 & 0.265 \\
\hline \multirow[t]{4}{*}{ rs2283265_rs4245146 } & GC & 0.450 & $0.448,0.450$ & 0.006 & 0.937 & 1.000 \\
\hline & GT & 0.370 & $0.376,0.367$ & 0.074 & 0.786 & 0.984 \\
\hline & $\mathrm{TC}$ & 0.129 & $0.143,0.123$ & 0.737 & 0.391 & 0.742 \\
\hline & $\mathrm{TT}$ & 0.052 & $0.033,0.059$ & 2.918 & 0.088 & 0.193 \\
\hline \multirow[t]{4}{*}{ rs4245146_rs4648317 } & $\mathrm{CC}$ & 0.426 & $0.442,0.419$ & 0.482 & 0.488 & 0.861 \\
\hline & $\mathrm{TC}$ & 0.403 & $0.392,0.408$ & 0.221 & 0.639 & 0.951 \\
\hline & $\mathrm{CT}$ & 0.152 & $0.147,0.153$ & 0.066 & 0.797 & 0.986 \\
\hline & $\mathrm{TT}$ & 0.019 & $0.018,0.020$ & 0.022 & 0.882 & 0.999 \\
\hline \multirow[t]{5}{*}{ rs1800497_rs6277_rs2283265 } & CTG & 0.479 & $0.473,0.482$ & 0.071 & 0.790 & 1.000 \\
\hline & $\mathrm{CCG}$ & 0.323 & $0.328,0.321$ & 0.049 & 0.824 & 1.000 \\
\hline & TCT & 0.153 & $0.173,0.145$ & 1.366 & 0.243 & 0.616 \\
\hline & TTT & 0.014 & $0.005,0.018$ & 2.638 & 0.104 & 0.324 \\
\hline & TTG & 0.014 & $0.016,0.013$ & 0.147 & 0.701 & 0.998 \\
\hline \multirow[t]{7}{*}{ rs6277_rs2283265_rs4245146 } & TGC & 0.261 & $0.249,0.265$ & 0.296 & 0.587 & 0.993 \\
\hline & TGT & 0.231 & $0.238,0.229$ & 0.105 & 0.746 & 0.998 \\
\hline & CGC & 0.188 & $0.198,0.185$ & 0.243 & 0.622 & 0.995 \\
\hline & CGT & 0.139 & $0.138,0.139$ & 0.002 & 0.964 & 1.000 \\
\hline & CTC & 0.119 & $0.139,0.112$ & 1.546 & 0.214 & 0.579 \\
\hline & CTT & 0.039 & $0.028,0.043$ & 1.332 & 0.248 & 0.649 \\
\hline & TTT & 0.013 & $0.005,0.016$ & 2.027 & 0.155 & 0.416 \\
\hline \multirow[t]{7}{*}{ rs2283265_rs4245146_rs4648317 } & GTC & 0.358 & $0.365,0.355$ & 0.102 & 0.750 & 1.000 \\
\hline & GCC & 0.311 & $0.318,0.309$ & 0.093 & 0.760 & 1.000 \\
\hline & GCT & 0.137 & $0.129,0.140$ & 0.241 & 0.624 & 0.999 \\
\hline & TCC & 0.113 & $0.123,0.109$ & 0.414 & 0.520 & 0.979 \\
\hline & TTC & 0.046 & $0.028,0.053$ & 3.296 & 0.070 & 0.207 \\
\hline & TCT & 0.016 & $0.020,0.015$ & 0.347 & 0.556 & 0.987 \\
\hline & GTT & 0.013 & $0.012,0.014$ & 0.085 & 0.771 & 1.000 \\
\hline \multirow[t]{6}{*}{ rs1800497_rs6277_rs2283265_rs4245146 } & CTGC & 0.257 & $0.245,0.261$ & 0.278 & 0.598 & 0.996 \\
\hline & CTGT & 0.223 & $0.228,0.221$ & 0.067 & 0.795 & 1.000 \\
\hline & CCGC & 0.188 & $0.197,0.185$ & 0.197 & 0.657 & 0.998 \\
\hline & CCGT & 0.135 & $0.131,0.136$ & 0.056 & 0.813 & 1.000 \\
\hline & TCTC & 0.116 & $0.141,0.106$ & 2.588 & 0.108 & 0.252 \\
\hline & TCTT & 0.037 & $0.033,0.039$ & 0.186 & 0.666 & 0.998 \\
\hline \multirow[t]{10}{*}{ rs6277_rs2283265_rs4245146_rs4648317 } & TGTC & 0.219 & $0.230,0.214$ & 0.296 & 0.586 & 1.000 \\
\hline & TGCC & 0.215 & $0.213,0.216$ & 0.012 & 0.911 & 1.000 \\
\hline & CGTC & 0.138 & $0.133,0.140$ & 0.086 & 0.769 & 1.000 \\
\hline & СТCC & 0.105 & $0.120,0.100$ & 0.935 & 0.333 & 0.927 \\
\hline & CGCC & 0.099 & $0.107,0.096$ & 0.263 & 0.608 & 1.000 \\
\hline & CGCT & 0.084 & $0.087,0.082$ & 0.073 & 0.787 & 1.000 \\
\hline & TGCT & 0.051 & $0.041,0.055$ & 0.792 & 0.374 & 0.951 \\
\hline & CTTC & 0.036 & $0.025,0.040$ & 1.405 & 0.236 & 0.785 \\
\hline & СТCT & 0.014 & $0.017,0.013$ & 0.309 & 0.579 & 1.000 \\
\hline & TTTC & 0.012 & $0.004,0.015$ & 1.961 & 0.161 & 0.609 \\
\hline rs1800497_rs6277_rs2283265 & CTGCC & 0.213 & $0.211,0.214$ & 0.013 & 0.910 & 1.000 \\
\hline \multirow[t]{2}{*}{ _rs4245146_rs4648317 } & CTGTC & 0.211 & $0.218,0.208$ & 0.125 & 0.724 & 1.000 \\
\hline & CCGTC & 0.133 & $0.124,0.136$ & 0.263 & 0.608 & 1.000 \\
\hline
\end{tabular}


Table IV. Continued.

\begin{tabular}{|c|c|c|c|c|c|c|}
\hline \multirow[b]{2}{*}{ Polymorphism } & \multirow[b]{2}{*}{ Haplotype } & \multicolumn{2}{|c|}{ Frequency } & \multirow[b]{2}{*}{$\chi^{2}$} & \multirow[b]{2}{*}{ P-value } & \multirow[b]{2}{*}{$\mathrm{p}_{\text {corr }}$ value $^{\mathrm{a}}$} \\
\hline & & All individuals & Case, control & & & \\
\hline & TCTCC & 0.103 & $0.122,0.096$ & 1.619 & 0.203 & 0.706 \\
\hline & CCGCC & 0.101 & $0.107,0.099$ & 0.159 & 0.691 & 1.000 \\
\hline & CCGCT & 0.083 & $0.086,0.081$ & 0.073 & 0.788 & 1.000 \\
\hline & CTGCT & 0.050 & $0.042,0.053$ & 0.544 & 0.461 & 0.994 \\
\hline & TCTTC & 0.034 & $0.030,0.036$ & 0.264 & 0.608 & 1.000 \\
\hline & ТСТСТ & 0.014 & $0.018,0.013$ & 0.537 & 0.464 & 0.994 \\
\hline
\end{tabular}

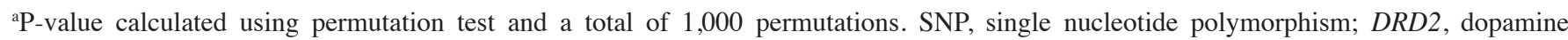
receptor D2.

for association with endometriosis using the Cochran-Armitage trend test (13). In order to adjust for the multiple testing, the Bonferroni correction was employed. A haplotype-based association analysis was performed using the Haploview software (http://www.broadinstitute.org/mpg/haploview; Broad Institute, Cambridge, MA, USA). P-values for both global and individual tests of haplotype distribution between cases and controls were calculated. Statistical significance was assessed using the 1,000-fold permutation testing with a cut-off of $<0.05$.

\section{Results}

Prevalence of the DRD2 rs1800497, rs6277, rs2283265, rs4245146 and rs4648317 SNPs in patients with endometriosis-related infertility. The distribution of the DRD2 rs1800497, rs6277, rs2283265, rs4245146 and rs4648317 SNP genotypes did not display deviation from the HWE in either the patient or control groups ( $\mathrm{P}>0.05)$. The number of genotypes, in addition to the ORs and 95\% CI intervals for these SNPs are stated in Table III. DRD2 rs1800497, rs6277, rs2283265, rs4245146 and rs4648317 SNP association was observed in neither the dominant nor recessive inheritance models of endometriosis-related infertility. The lowest P-values of the trend test were observed for DRD2 rs6277 in women with endometriosis-related infertility (ptrend $=0.435$ ).

Association of DRD2 haplotypes with endometriosis-related infertility. Haplotype analysis of the DRD2 rs1800497, rs6277, rs2283265, rs4245146 and rs4648317 SNPs did not reveal these polymorphisms to be risk factors for endometriosis-related infertility (Table IV). The lowest global $\mathrm{P}=0.070, \mathrm{p}_{\text {corr }}=0.207$, refers to haplotypes comprising DRD2 rs2283265, rs4245146 and rs4648317 (Table IV).

\section{Discussion}

Dopamine receptors are members of the $\mathrm{G}$ protein-coupled receptors and contain seven transmembrane domains. The DRD2 gene is situated on chromosome 11q and encodes the D2 subtype of the dopamine receptor. Previously, a number of genetic studies have demonstrated the significance of SNPs located in the DRD2 gene in various neurological and psychiatric disorders, including severe alcoholism, schizophrenia, migraine, post-traumatic stress disorder and addictive disorders $(14,15)$. Furthermore, Hansen et al (10) showed that DRD2 gene rs6275 was a genetic risk factor for hyperprolactinemia.

Recently, Bilibio et al (11) demonstrated an association between DRD2 rs6277 and endometriosis in infertile women from the Brazilian population (11). The authors also suggested that this polymorphism may lead to a defect in post-receptor signaling, causing a mild upregulation of prolactin serum levels. Thus, prolactin may promote angiogenesis of ectopic endometrial implants (11). However, in the present study, no association between DRD2 rs1800497, rs6277, rs2283265, rs4245146 and rs4648317 SNPs and endometriosis-related infertility was observed. The differences in the effect of DRD2 polymorphisms on the development of endometriosis-related infertility in the current study may be due to racial heterogeneity, the small study population, or distinct environmental factors.

To date, the genetic variants of DRD2 have been shown to be involved in the pharmacokinetics and pharmacodynamics of antipsychotic drugs, which may produce varying effects on prolactin secretion (9,16-23). The $D R D 2 /$ ankyrin repeat and kinase domain containing 1 (ANKK1) Taq1A polymorphism (rs1800497) is situated in the ANKK1 gene, which is downstream from $D R D 2$ and creates two allelic variants, A1 and A2 (17,18). The DRD2/ANKK1 rs1800497 A1 allele, is linked to a reduced density of $D R D 2$ in the striatum $(17,18)$. Patients with the A1 allele, who were currently receiving antipsychotics, displayed hyperprolactinemia, compared with individuals without this allele $(9,19,20)$. Aklillu et al (21) observed that carriers of the A1/A1 genotype exhibited an increase in prolactin level at $2 \mathrm{~h}$ following treatment with an antipsychotic drug. The DRD2 Taq1A SNP also produced an effect on prolactin levels, when induced by atypical antipsychotic drugs in healthy volunteers (22). In addition to these findings, clinical trials have also shown that the DRD2 rs2734842, rs1076562, rs6275 and rs6279 SNPs are associated with hyperprolactinemia during antipsychotic treatment $(23,24)$.

Despite the association of DRD2 SNPs with hyperprolactinemia and infertility, the present study failed to demonstrate an association between the selected SNPs and endometriosis-related infertility. In conclusion, the current 
study requires replication in a larger study population, with varying ethnicity and environmental exposures, for example to different pollutants and toxins, in order to confirm or refute the association between these SNPs and endometriosis-related infertility.

\section{Acknowledgements}

The present study was supported by Poznań University of Medical Sciences (grant no. 502-01-01124182-07474).

\section{References}

1. Gregoriou G, Bakas P, Vitoratos N, Papadias K, Goumas K, Chryssicopoulos A and Creatsas G: Evaluation serum prolactin levels in patients with endometriosis and infertility. Gynecol Obstet Invest 48: 48-51, 1999.

2. Panidis D, Vavilis D, Rousso D, Panidou E and Kalogeropoulos A: Provocative tests of prolactin before, during and after long-term danazol treatment in patients with endometriosis. Gynecol Endocrinol 6: 19-24, 1992.

3. Wang $\mathrm{H}$, Gorpudolo $\mathrm{N}$ and Behr B: The role of prolactin- and endometriosis-associated infertility. Obstet Gynecol Surv 64 542-547, 2009.

4. Reese J, Binart N, Brown N, Ma WG, Paria BC, Das SK, Kelly PA and Dey SK: Implantation and decidualization defects in prolactin receptor (PRLR)-deficient mice are mediated by ovarian but not uterine PRLR. Endocrinology 141: 1872-1881, 2000.

5. Novella-Maestre E, Carda C, Noguera I, Ruiz-Saurí A, García-Velasco JA, Simón C and Pellicer A: Dopamine agonist administration causes a reduction in endometrial implants through modulation of angiogenesis in experimentally induced endometriosis. Hum Reprod 24: 1025-1035, 2009.

6. Ben-Jonathan N, LaPensee CR and LaPensee EW: What can we learn from rodents about prolactin in humans? Endocr Rev 29 $1-41,2008$.

7. Missale C, Nash SR, Robinson SW, Jaber M and Caron MG: Dopamine receptors: From structure to function. Physiol Rev 78: 189-225, 1998.

8. Nilsson C and Eriksson E: Partial dopamine D2 receptor agonists antagonize prolactin-regulating D2 receptors in a transfected clonal cell line (GH4ZR7). Eur J Pharmacol 218: 205-211, 1992.

9. Calarge CA, Ellingrod VL, Acion L, Miller DD, Moline J, Tansey MJ and Schlechte JA: Variants of the dopamine D2 receptor gene and risperidone-induced hyperprolactinemia in children and adolescents. Pharmacogenet Genomics 19: 373-382, 2009.

10. Hansen KA, Zhang Y, Colver R, Tho SP, Plouffe L Jr and McDonough PG: The dopamine receptor D2 genotype is associated with hyperprolactinemia. Fertil Steril 84: 711-718, 2005.
11. Bilibio JP, Matte U, de Conto E, Genro VK, Souza CA and Cunha-Filho JS: Dopamine receptor D2 genotype (3438) is associated with moderate/severe endometriosis in infertile women in Brazil. Fertil Steril 99: 1340-1345, 2013

12. Canis M, Donnez JG, Guzick DS, Halme JK, Rock JA, Schenken RS and Vernon MW: Revised American Society for Reproductive Medicine classification of endometriosis: 1996. Fertil Steril 67: 817-821, 1997.

13. Sasieni PD: From genotypes to genes: Doubling the sample size. Biometrics 53: 1253-1261, 1997.

14. Comings DE and Blum K: Reward deficiency syndrome: Genetic aspects of behavioral disorders. Prog Brain Res 126: 325-341, 2000.

15. Noble EP: D2 dopamine receptor gene in psychiatric and neurologic disorders and its phenotypes. Am J Med Genet B Neuropsychiatr Genet 116B: 103-125, 2003.

16. Caccavelli L, Cussac D, Pellegrini I, Audinot V, Jaquet P and Enjalbert A: D2 dopaminergic receptors: Normal and abnormal transduction mechanisms. Horm Res 38: 78-83, 1992.

17. Thompson J, Thomas N, Singleton A, Piggott M, Lloyd S, Perry EK, Morris CM, Perry RH, Ferrier IN and Court JA: D2 dopamine receptor gene (DRD2) Taq1 A polymorphism: Reduced dopamine D2 receptor binding in the human striatum associated with the A1 allele. Pharmacogenetics 7: 479-484, 1997.

18. Noble EP, Blum K, Ritchie T, Montgomery A and Sheridan PJ: Allelic association of the D2 dopamine receptor gene with receptor-binding characteristics in alcoholism. Arch Gen Psychiatry 48: 648-654, 1991

19. Young RM, Lawford BR, Barnes M, Burton SC, Ritchie T, Ward WK and Noble EP: Prolactin levels in antipsychotic treatment of patients with schizophrenia carrying the DRD2*A1 allele. Br J Psychiatry 185: 147-151, 2004.

20. Mihara K, Suzuki A, Kondo T, Yasui-Furukori N, Ono S, Otani K, Kaneko S and Inoue Y: Relationship between Taq1 A dopamine D2 receptor (DRD2) polymorphism and prolactin response to bromperidol. Am J Med Genet 105: 271-274, 2001.

21. Aklillu E, Kalow W, Endrenyi L, Harper P, Miura J and Ozdemir V: CYP2D6 and DRD2 genes differentially impact pharmacodynamic sensitivity and time course of prolactin response to perphenazine. Pharmacogenet Genomics 17: 989-993, 2007.

22. López-Rodríguez R, Román M, Novalbos J, Pelegrina ML, Ochoa D and Abad-Santos F: DRD2 Taq1A polymorphism modulates prolactin secretion induced by atypical antipsychotics in healthy volunteers. J Clin Psychopharmacol 31: 555-562, 2011.

23. Houston JP, Fijal B, Heinloth AN and Adams DH: Genetic associations of prolactin increase in olanzapine/fluoxetine combination-treated patients. Psychiatry Res 175: 171-172, 2010

24. Houston J, Dharia S, Bishop JR, Ellingrod VL,Fijal B, Jacobson JG and Hoffmann VP: Association of DRD2 and ANKK1 polymorphisms with prolactin increase in olanzapine-treated women. Psychiatry Res 187: 74-79, 2011. 